\title{
Preview: 2018 Materials Research Society Spring Meeting \& Exhibit
}

\author{
Phoenix Convention Center, Phoenix, Arizona | Meeting: April 2-6 | Exhibit: April 3-5 \\ www.mrs.org/spring2018
}

$\mathrm{T}$ he 2018 Materials Research Society (MRS) Spring Meeting will be held at the Phoenix Convention Center (PCC), April 2-6. The scientific sessions will include many new and developing areas of materials research, as well as some well-established and popular topics. To complement the scientific symposia, 14 tutorials will provide detailed introductions to particularly exciting areas of research, while the exhibit will showcase products of interest to the materials community.

Making up the core of the Meeting are six topical clusters of the technical program, encompassing 61 symposia plus two Late News-Hot Topics symposia: Materials Science to Empower Quantum Information Technologies and Artificial Intelligence for Materials Development Forum. The symposia are grouped as follows:

Characterization, Modeling and Theory-This cluster includes six symposia with a focus on simulation, theory, and advanced nanoscale characterization of materials and of their functional properties by transmission electron microscopy; electron, x-ray, and neutron diffraction; and scanning probe microscopy and spectroscopy techniques. Special emphasis is placed on in situ investigations of materials as well as their operando characterization. Spatiotemporal deformation mechanisms of materials and their dynamics are also addressed.

Electronic and Photonic MaterialsThis cluster comprises eight symposia with a focus on processing, characterization, integration, device performance, and reliability issues of materials for electronics, photonics, and optoelectronics applications. Materials for advanced memory and low power logic applications and their implementation in 3D architectures and in nonconventional computing, as well as materials for quantum technologies, light-emitting diodes, novel emitters, lasers, photovoltaics, and highly integrated optoelectronic circuits, will be addressed.

Energy Materials and Technologies This cluster is comprised of 21 symposia that address the challenges, opportunities, and technologies related to energy materials, devices, and systems. Specific topical areas include photovoltaic materials and devices (perovskite and novel inorganic semiconductors), energy storage (batteries, capacitive devices, fuel cells, electrochemical systems, thermoelectrics, super ion conductors, and interfaces), solar fuels, nuclear materials, superconductivity, as well as advanced materials for carbon capture, sustainable energy, and grid energy storage.

Manufacturing-The manufacturing cluster features five symposia dedicated to a wide range of materials and applications: 1D nanowires, 2D materials, composites, textiles, as well as materials aimed at particular applications, such as advances in additive manufacturing, digital and analog printing technologies, organic electronics, direct matter assembly, and dynamic materials. Many of the symposia will establish connections to methods for characterization and possible applications.

Nanomaterials-The nanomaterials cluster features 13 symposia dedicated to a wide range of nanoscale science and technologies of a variety of organic, inorganic, and hybrid materials suitable

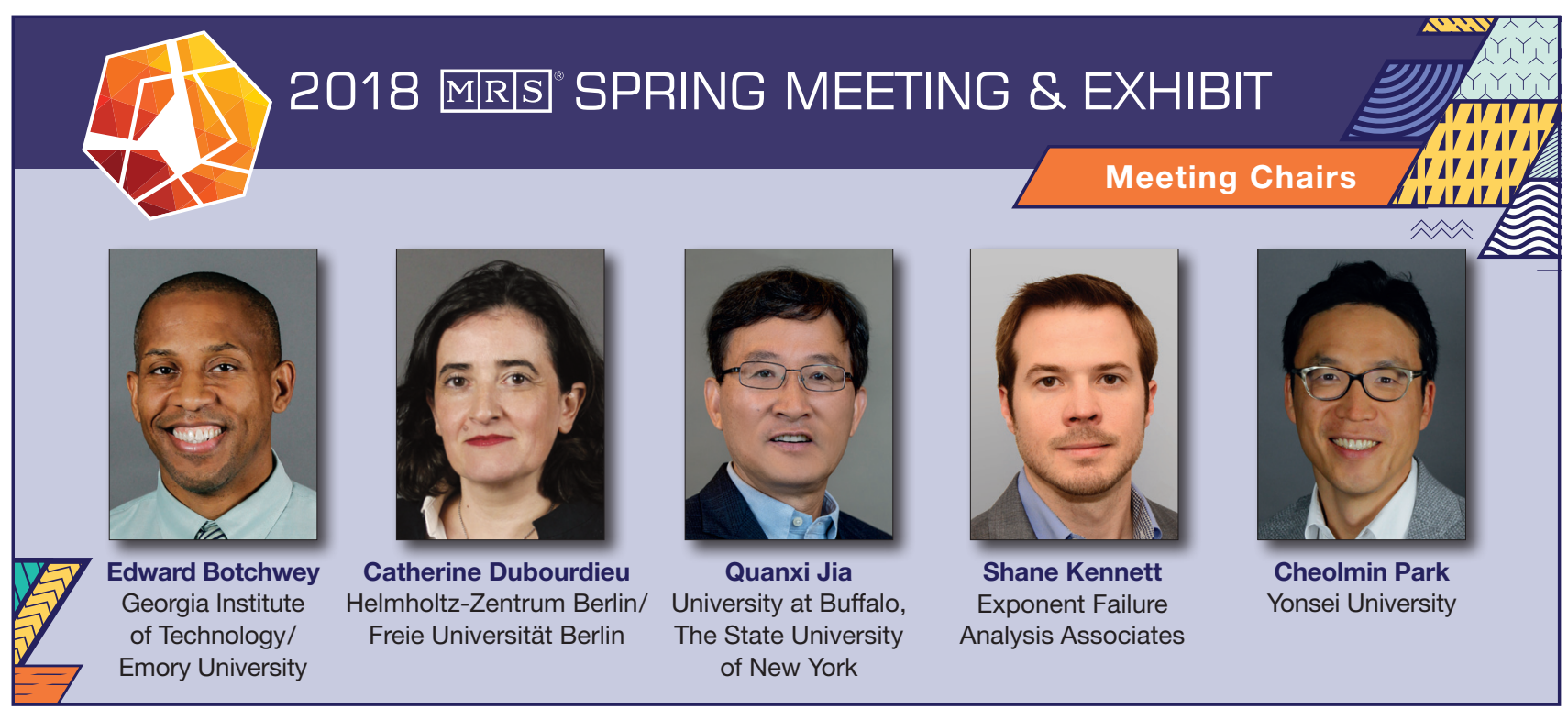




\begin{tabular}{|c|c|c|}
\hline C & $\begin{array}{l}\text { PREREGISTRATION } \\
\text { before 5:00 pm (ET) } \\
\text { March 16, } 2018\end{array}$ & $\begin{array}{c}\text { ON-SITE REGISTRATION } \\
\text { after 5:00 pm (ET) } \\
\text { March 16, 2018 }\end{array}$ \\
\hline Meeting Registration & $\$ 670$ & $\$ 795$ \\
\hline Meeting Registration with MRS Member Discount & $\$ 530$ & $\$ 660$ \\
\hline Student Registration & $\$ 150$ & $\$ 185$ \\
\hline Student Registration with MRS Member Discount & $\$ 120$ & $\$ 150$ \\
\hline Unemployed & $\$ 150$ & $\$ 180$ \\
\hline Retired & $\$ 180$ & $\$ 200$ \\
\hline
\end{tabular}

2018 MRS Spring Meeting registrations include MRS Membership from July 1, 2018 to June 30, 2019.

for emerging photoelectric, photocatalytic, and structural applications. Topics include cutting-edge nanoscale top-down and bottom-up fabrication processes based on cluster deposition and self-assembly, novel synthesis methods for hierarchical nanoporous materials, nanocomposites, carbon-based nanomaterials, and scalable light-emitting quantum dots. New plasmonic and metamaterials, structural nano-metallic materials, atomically thin layered materials, magnetic, and topological nanomaterials will also be addressed.
Soft Materials and BiomaterialsThere are eight symposia in this broad interdisciplinary cluster. Key topics include fundamental and applied research in the following technical areas: intelligent and biologically inspired materials, bioelectronics, immune modulatory materials, soft robotics, neural interfaces, and advanced polymeric materials.

Lunchtime Symposium X Presentations will include the Outstanding Young Investigator Award Talk, MRS Communications Lecture, Innovation in Materials
Characterization Award Talk, and the MidCareer Researcher Award Talk. The Fred Kavli Distinguished Lectureship in Materials Science Plenary presentation will be held Tuesday morning in PCC North.

An interactive workshop, "Designing Sustainability into Materials Research," will be offered Monday, April 2 from 2:00 pm to 4:30 pm in PCC North. Preregistration is required at www.mrs.org/ sustainability-rsvp. Alan Rae will present the seminar "Real-Life Challenges and Opportunities in Sustainable Product Design" Tuesday from 7:30 pm to 8:30 pm in the Sheraton. The panel discussion "Materials Needs for Energy Sustainability by $2050-100 \%$ Replacement of Fossil Fuels by Sustainable Alternatives" will be held Wednesday from 7:30 pm to 9:00 pm in PCC North.

The MRS/Cambridge University Press Publications Booth 100 will be featured in the Exhibit Hall. Stop by to learn about the MRS Publications Portfolio, and "Reimagine your Reality" by picking up a pair of VR glasses.

"Essentials of Getting Your Work Published" will be held Monday from 3:30 pm to 5:00 pm in PCC North.

\section{Tutorials $\square$ Monday, April 2}

The 2018 MRS Spring Meeting will feature 14 tutorials covering a variety of topics to complement the symposium sessions.

Tutorials are free of charge for all registered attendees. Tutorial notes will be available for purchase at the preregistration price of $\$ 35$.

After the preregistration period ends, notes will be available for purchase for $\$ 45$ on-site at the MRS/Cambridge Publications Booth 100 in the Exhibit Hall. All tutorials will be held in the Phoenix Convention Center on Monday, April 2.

\begin{tabular}{|l|l}
\hline CM04 & $\begin{array}{l}\text { In Situ and Operando Characterization } \\
\text { of Materials and Devices } \\
1: 30 \mathrm{pm}-5: 00 \mathrm{pm}\end{array}$ \\
\hline EN19 & $\begin{array}{l}\text { High-Throughput Computational } \\
\text { and Experimental Approaches } \\
\text { to Materials Discovery } \\
\text { 1:30 pm-5:00 pm }\end{array}$ \\
\hline EN20 & $\begin{array}{l}\text { Electrochemical Interfacial Methods } \\
\text { for Energy Systems }\end{array}$ \\
& 8:00 am-12:00 pm \\
EP01 & Materials and Devices for III-V 3D \\
M0S and Negative Capacitance FETs \\
1:30 pm-5:00 pm \\
Reliability of Semiconductor Optical \\
and Electron Devices and Materials \\
8:00 am-5:00 pm
\end{tabular}

\begin{tabular}{|c|l} 
EP05 & $\begin{array}{l}\text { Emerging Low-Dimensional and } \\
\text { Perovskite Light-Emitting Materials } \\
\text { and Devices } \\
\text { 8:00 am-5:00 pm }\end{array}$ \\
EP07 & $\begin{array}{l}\text { Phase-Change Materials-Basic } \\
\text { Research to Industrial Applications } \\
\text { 8:00 am-5:00 pm }\end{array}$ \\
MA03 & $\begin{array}{l}\text { Experimental and Theoretical } \\
\text { Methods for Atomic Scale } \\
\text { Manipulation of Matter } \\
\text { 1:30 pm-5:00 pm }\end{array}$ \\
NM04 & $\begin{array}{l}\text { Understanding Porosity and Catalytic } \\
\text { Properties of Porous Materials and } \\
\text { Nanocomposites } \\
\text { 1:30 pm-5:00 pm }\end{array}$ \\
\end{tabular}

NM06 Nanodiamonds for Applications in Composites 1:30 pm-5:00 pm

NM07 Magnetism at Nanoscale 8:00 am-12:00 pm Plasmonics, Metamaterials and Metasurfaces for Manipulating Light at the Nanoscale 8:00 am-5:00 pm

NM13 Topological PhenomenaTheory to Applications 1:30 pm-5:00 pm

SM06 Understanding Recording and Stimulation in Electrophysiology 8:00 am-12:00 pm 
Learn the fundamentals of successful scientific publishing from MRS journal Editors-in-Chief.

Poster sessions will be held in the PCC North Exhibit Hall on Tuesday through Thursday from 2:00 pm to 7:00 $\mathrm{pm}$. Poster presenters will be available to discuss their research from 5:00 pm to 7:00 $\mathrm{pm}$. The Meeting chairs will recognize the best presentations each day of the poster sessions. One or more awards of up to $\$ 500$ will be presented based on the posters' technical content, appearance, graphic excellence, and presentation quality.

The popular Science as Art competition will be held again at this Meeting. The competition is open to all registered Meeting attendees. Multiple first-place and second-place awards of $\$ 400$ and $\$ 200$, respectively, will be presented at the Meeting. Guidelines are listed on the 2018 MRS Spring Meeting website.

MRS will host a Career Fair in the Exhibit Hall to connect job seekers with recruiters to explore available career opportunities. Attendees can discuss their qualifications directly with recruiters, participate in mock interviews, and have their photo taken professionally. Register online and upload your resume at jobs.mrs.org or stop by the Career Fair to access the registration stations.

The Student Mixer will be held Monday evening from 7:00 pm to 8:00 pm in the Sheraton Grand Phoenix hotel. All students are invited to attend.

Wednesday afternoon, the Wearables in Smart Fabrics Fashion Show will showcase tech design innovators, researchers, and fashion students from Arizona State University. It will feature new possibilities of fashion through the lens of technology in the form of speculative design. Also, create, capture, and share your MRS Spring Meeting experiences at the Selfie Station located in the Exhibit Hall.

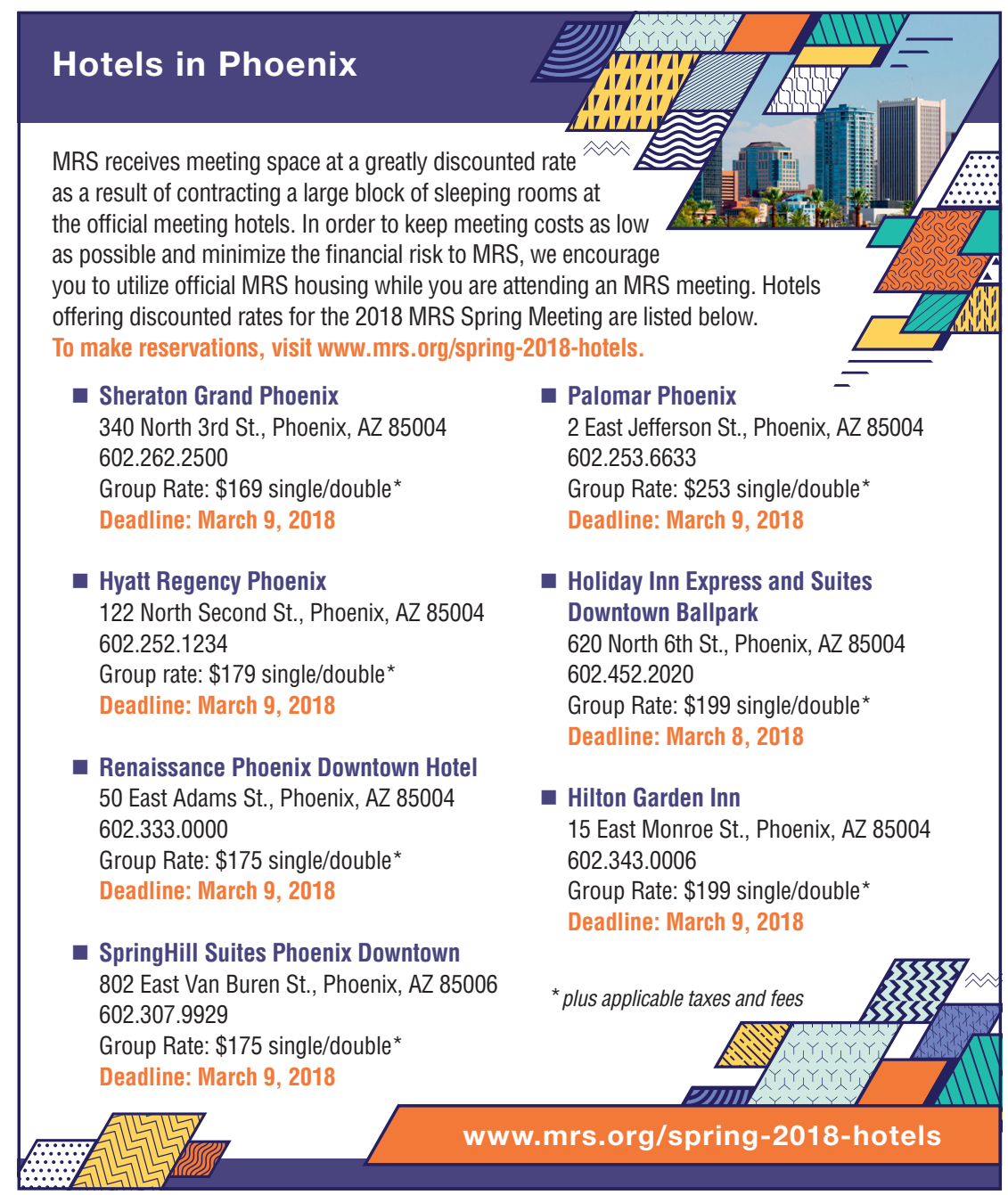

Materials Voice will be available onsite Tuesday through Thursday in the Exhibit Hall for members to help in support of sustained federal research funding. It is quick and easy to send letters on funding and current policy issues that are important to the materials research community. There will also be a Research Funding Opportunities session on Monday from 5:30 pm to 8:00 pm. Invited talks will consist of a 20-minute introduction centered on the overall focus of the agency's materials science research efforts, programmatic descriptions of how to collaborate or apply, and other general details. These talks will be followed by roundtable discussion with each program manager.

The deadline to preregister for the MRS Spring Meeting is March 16, 2018 (5:00 pm ET). International travelers are reminded to begin the visa process early. For additional information on the Spring Meeting, contact MRS Member Services, e-mail info@ mrs.org; and tel. 724-779-3003. For the most up-to-date event listings, visit www.mrs.org/spring2018.

\section{FOR DISCOUNTED PRICING ON MATERIALS-RELATED TITLES}

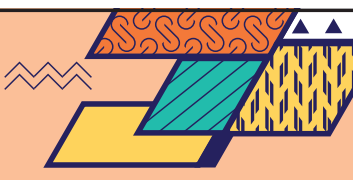

